\title{
ANALISIS FAKTOR YANG BEHUBUNGAN DENGAN JENIS PERSALINAN PADA IBU HAMIL
}

\author{
Sitti Fatimah ${ }^{1}$, A. Ulfa Fatmasaanti ${ }^{2}$ \\ ${ }^{1}$ Akademi Kebidanan Batari Toja Watampone \\ email: Sittifatimah117@gmail.com \\ ${ }^{2}$ Akademi Kebidanan Batari Toja Watampone \\ email: andiulfafatmasanti@gmail.com
}

\begin{abstract}
Background Maternal and child health efforts are efforts in the health sector related to the service and maintenance of pregnant women, childbirth, breastfeeding, infants, and toddlers and preschoolers. The mode of delivery is a number of methods chosen by the mother who delivered and by the health worker who handled it. Mochtar divides the type of labor according to the way labor is divided into two categories, normal (spontaneous) labor, which is the birth of the baby behind the head with the mother's own power and abnormal delivery, namely labor with the help of a tool or through the abdominal wall by caesarean surgery.

Purpose to find out the factors of labor in pregnant women.

Methods This type of research is analytic observational cross-sectional study of women giving birth at the Sibulue puskesmas in the period from December 2019 to February 2020 with a large sample of 67 women giving birth. Data obtained from medical records

The results of this study indicate abnormal labor with actions related to the incidence of severe asphyxia $(p=0,000 ; \mathrm{Cl}: 1.19-2.06)$ and Low Birth Weight ( $p=0,000 ; \mathrm{Cl}: 1.28-2.05)$. Number of Antenatal Care Examination <4 times associated with the abnormal labor process Action ( $p=0.046$; Cl: 1.04-1.46)

Conclusion in this study is the relationship between the delivery process with Antenatal Care examination on the outcome of labor with the incidence of severe asphyxia and Low Bith Weight. Abnormal deliveries with complications occur in women with Antenatal examination < 4 times.

Suggestions for health care workers to further increase the early detection of risk factors in pregnant women by actively monitoring women during pregnancy.
\end{abstract}

Keywords: antenatal examination, type of labor, maternal mother

\section{ABSTRAK}

Latar Belakang Upaya kesehatan ibu dan anak adalah upaya bidang kesehatan terkait pelayanan dan pemeliharaan ibu hamil, bersalin, menyusui, bayi, dan anak balita serta anak prasekolah. Cara persalinan adalah beberapa metode yang dipilih oleh ibu yang melakukan persalinan maupun oleh tenaga kesehatan yang menanganinya. Mochtar membagi jenis persalinan menurut cara persalinan berdasarkan dua kategori, persalinan normal (spontan) yaitu proses lahirnya bayi letak belakang kepala dengan tenaga ibu sendiri dan persalinan abnormal, yaitu persalinan dengan bantuan alat atau melalui dinding perut dengan cara operasi caesarea.

Penelitian ini bertujuan untuk mengetahu factor proses persalinan pada Ibu hamil.

Metode Jenis penelitian ini analitik observatif cross-sectional terhadap wanita yang melahirkan di puskesmas Sibulue pada periode bulan desember 2019 hingga Februari 2020 dengan besar sampel 67 wanita yang melahirkan. Data diperoleh dari catatan medis.

Hasil penelitian ini menunjukan persalinan abnormal dengan tindakan berhubungan dengan kejadian Asfiksia Berat ( $p=0,000 ; \mathrm{Cl}: 1.19-2.06)$ dan Berat badan Lahir Rendah ( $\mathrm{p}=0,000 ; \mathrm{Cl}: 1.28-2.05)$. Jumlah Pemeriksaan Antenatal care $<4$ Kali berhubungan dengan proses persalinan abnormal Tindakan ( $p=0,046 ; \mathrm{Cl}$ : 1.04-1.46).

Kesimpulan pada penelitian ini adanya hubungaan proses persalinan dengan pemeriksaan Antenatal Care pada hasil persalinan dengan kejadian asfiksia berat dan Berat Badan Lahir Rendah. Persalinan abnormal dengan komplikasi terjadi pada ibu dengan pemeriksaan Antenatal <4 kali.

Saran bagi petugas pelayanan kesehatan agar lebih meningkatkan deteksi dini faktor risiko pada ibu hamil dengan pemantauan secara aktif pada ibu semasa hamil.

Kata Kunci : Pemeriksaan antenatal, jenis persalinan, ibu hamil 


\section{PENDAHULUAN}

Upaya kesehatan ibu dan anak adalah upaya bidang kesehatan terkait pelayanan dan pemeliharaan ibu hamil, bersalin, menyusui, bayi, dan anak balita serta anak prasekolah. Seorang ibu berperan penting dalam pertumbuhan bayi dan perkembangan anak. Gangguan kesehatan yang dialami ibu hamil mempengaruhi kesehatan janin sampai masa anak-anak (Kemenkes RI, 2017). Tujuan pembangunan kesehatan tertuang dalam deklarasi Millennium Development Goal's (MDGs), targetnya adalah menurunkan Angka Kematian Ibu(AKI) menjadi 102/100.000 kelahiran hidup pada tahun 2015, namun tujuan MDGs belum tercapai sehingga dilanjutkan dengan Sustainable Development Goals (SDGs) dengan penurunan AKI menjadi 70/100.000 kelahiran hidup pada tahun 2030 (Kemenkes RI, 2017).

Antenatal Care adalah asuhan yang diberikan ibu sebelum persalinan, dan prenatal care dan merupakan pelayanan untuk memonitor, mendukung kesehatan ibu dan mendeteksi ibu apakah ibu hamil normal atau bermasalah, asuhan standar minimal $7 \mathrm{~T}$ antara lain: timbangan berat badan, dan pengukuran tinggi badan, ukur tekanan darah, ukur tinggi fundus uteri, pemberian imunisasi Tetanus Toxoid (TT) lengkap, pemberian tablet besi minimal 90 tablet selama kehamilan,tes terhada penyakit menular seksual, temu wicara ( Xanda, Adhesty Novita, 2014). Antenatal Care ini penting dilakukan karena dalam pemeriksaan kehamilan tersebut dilakukan monitoring dan evaluasi secara menyeluruh baik mengenai kondisi ibu maupun janin yang sedang dikandungnya, sehingga dengan pemeriksaan kehamilan tersebut dapat diketahui perkembangan kehamilan, tingkat kesehatan kandungan, bahkan penyakit atau kelainan pada kandungan (Lihu, Fahmi A, Umbo, J.M.L, Kandou, G.D, 2014).

Persalinan yang aman adalah Persalinan dan kelahiran normal dengan proses pengeluaran janin yang terjadi pada kehamilan cukup bulan (3742 minggu), lahir spontan dengan presentasi belakang kepala yang berlangsung dalam 18 jam, tanpa komplikasi baik pada ibu maupun pada janin (Prawirohardjo,2002).

Cara persalinan adalah beberapa metode yang dipilih oleh ibu yang melakukan persalinan maupun oleh tenaga kesehatan yang menanganinya. Mochtar membagi jenis persalinan menurut cara persalinan berdasarkan dua kategori, persalinan normal (spontan) yaitu proses lahirnya bayi letak belakang kepala dengan tenaga ibu sendiri dan persalinan abnormal, yaitu persalinan dengan bantuan alat atau melalui dinding perut dengan cara operasi caesarea ( Rustam, Mochtar. 1998)

Keberhasilan sebuah proses persalinan sangat dipengaruhi oleh kondisi fisik ibu dan bayi, kondisipsikis maupun penolong yang membantu proses persalinan. Bila salah satu dari factor tersebut ada yang tidak sesuai bias terjadi masalah dalam proses persalinan, baik terhadap ibu maupun bayi. ( Asrinah dkk, 2010).

Upaya untuk mencegah adanya komplikasi obstetri bila mungkin dan memastikan bahwa komplikasi dideteksi sedini mungkin serta ditangani secara memadai dengan dilakukannya ANC (Saifuddin dkk, 2008). Keuntungan ANC adalah untuk dapat mengetahui berbagai risiko dan komplikasi hamil sehingga ibu hamil dapat diarahkan untuk melakukan rujukan ke rumah sakit (Manuaba, 2001).

Penelitian sebelumnya yang dilakukan oleh Dewi (2009) dalam Surniati, dkk yang menunjukkan adanya hubungan yang bermakna antara kematian perinatal dengan frekuensi antenatal care. Berkaitan dengan kematian ibu, dan pada penelitian Noor (2010) dalam Surniati, dkk menyebutkan bahwa ibu yang kurang dari 4 kali memeriksakan kehamilannya 4,57 kali lebih besar terjadi kematian maternal dibandingkan ibu yang melakukan pemeriksaan antenatal care 4kali atau lebih secara teratur.

Dari data diatas salah satu upaya untuk meningkatkan persalinan yang aman adalah deteksi dini mengenai pemeriksaan kehamilan yang harus dilakukan minimal 4 kali selama hamil dengan demikian penelitian ini bertujuan untuk mengetahui sejauh mana hubungan jumlah pemeriksaan kehamilan dengan proses persalina

\section{METODE PENELITIAN}

Penelitian ini merupankan penelitian suatu studi analitik observatif cross-sectional. Populasi dalam penelitian ini adalah seluruh data ibu bersalin yang bersalin di puskesmas Sibulue pada periode bulan desember 2019 hingga februari 2020. Dalam penelitian ini teknik pengambilan sampel secara total sampling yang berjumlah 67 ibu yang melahirkan. Data yang dikumpulkan dari catatan medis adalah data pribadi, jumlah pemeriksaan antenatal, jenis persalinan normal atau abnormal, skor Apgar dan berat badan bayi lahir. Data dianalisis dengan menggunakan program SPSS. Analisis bivariate menggunakan chi-square dengan $a<0,005$. 


\section{HASIL PENELITIAN}

Dari data yang di dapatkan di puskesmas sibulue mulai bulan desember 2019 sampai februari 2020 terdapat 67 ibu yang melahirkan .

Tabel 1.

\section{Distribusi Sampel Faktor Yang Behubungan Dengan Jenis Persalinan Pada Ibu Hamil}

\begin{tabular}{lcc}
\hline Kategori & $\mathrm{n}$ & $\%$ \\
\hline Umur (Tahun) & & \\
$<20$ & 8 & 11.9 \\
$20-35$ & 46 & 68.7 \\
$>35$ & 13 & 19.4 \\
Jumlah Pemeriksaan ANC & & \\
$<4$ kali & 20 & 29.9 \\
$\geq 4$ kali & 47 & 70.1 \\
Jenis Persalinan & & \\
Spontan & 59 & 88.1 \\
Tindakan & 8 & 11.9 \\
APGAR Score & & \\
0-3 & 8 & 11.9 \\
4-6 & 3 & 4.5 \\
7-10 & 56 & 83.6 \\
Berat Badan Lahir & & \\
$<2500$ gram & 9 & 13.4 \\
2500-4000 gram & 58 & 86.6 \\
\hline
\end{tabular}

Hasil analisis statistik menunjukan persalinan spontan dan tindakan mendapatkan hasil fetus yang dinilai berdasarkan skor Apgar. Dengan hasil yang melahirkan dengan tindakan berhubungan dengan kejadian asfiksia berat $(p=0,000)$. Persalinan spontan lebih banyak melahiran bayi dengan nilai skor Apgar yang segar bugar sebaliknya dengan persalinan dengan tindakan lebih banyak yang mengalami nilai skor Apgar pada asfiksia Berat.

Hasil analisis statistic menunjukan ada hubungan antara persalinan spontan dengan berat badan lahir bayi dimana ibu yang melahirkan dengan tindakan akan beresiko $13,4 \%$ akan melahirkan anak dengan berat badan kurang dari 2500 gram ( $\mathrm{Cl}=0.99-1.08)$

Hasil analisis statistic menunjukan ada hubungan antara jumlah pemeriksaan antenatal $<4$ kali dengan persalinan dengan tindakan $(p=0,046)$. lbu dengan jumlah pemeriksaan antenatal $>4$ kali lebih banyak melakukan persalinan spontan, sebaliknya ibu dengan jumlah pemeriksaan antenatal < 4 kali lebih banyak melakukan persalinan dengan tindakan.

Tabel 2.

Analisis Faktor Yang Behubungan Dengan Jenis Persalinan Pada Ibu Hamil

\begin{tabular}{|c|c|c|c|c|c|c|}
\hline V.Terikat & Kategori & Spontan & Tindakan & $\%$ & $95 \% \mathrm{Cl}$ & $P<0.05$ \\
\hline \multirow[t]{4}{*}{ Hasil Persalinan } & APGAR Score & & & & & \multirow{4}{*}{0.000} \\
\hline & Asfiksia Berat (0-3) & 3 & 5 & 11.9 & $1.19-2.06$ & \\
\hline & Asfiksia Ringan-Sedang (4-6) & 1 & 2 & 4.5 & $0.23-3.10$ & \\
\hline & Bugar (7-10) & 55 & 1 & 83.6 & $0.98-1.05$ & \\
\hline \multirow{5}{*}{$\begin{array}{l}\text { Berat Badan Lahir } \\
\text { (Kg) } \\
\text { Umur }\end{array}$} & $<2500$ gram & 3 & 6 & 13.4 & $1.28-2.05$ & \multirow{2}{*}{0.000} \\
\hline & $2500-4000$ gram & 56 & 2 & 86.6 & $0.99-1.08$ & \\
\hline & $<20$ tahun & 7 & 1 & 11.9 & $0.83-1.42$ & \multirow{3}{*}{0.786} \\
\hline & 20-35 tahun & 41 & 5 & 68.7 & $1.02-1.20$ & \\
\hline & $>35$ tahun & 11 & 2 & 19.4 & $0.93-1.38$ & \\
\hline Jumlah & $<4$ kali & 15 & 5 & 29.9 & $1.04-1.46$ & \multirow{2}{*}{0.046} \\
\hline Pemeriksaan ANC & $\geq 4$ kali & 44 & 3 & 70.1 & $0.99-1.14$ & \\
\hline
\end{tabular}

\section{PEMBAHASAN}

Berdasarkan hasil penelitian yang dilakukan di puskesmas sibulue diperoleh bahwa proporsi responden yang melahirakn pada bulan desember 2019 sampai dengan bulan februari 2020 sejumlah 67 ibu hamil dimana ibu yang melahirkan spontan terdapat $88,1 \%$ dari 59 ibu dan $11,9 \%$ dari 8 ibu yang melahirkna dengan tindakan. Pada penelitian ini jenis persalinan dikelompokkan menjadi dua yakni persalinan spontan dan persalinan dengan tindakan. Hasil penelitian menunjukkan bahwa jumlah pemeriksaan antenatal berhubungan dengan jenis persalinan. Persalinan spontan lebih banyak terjadi pada kelompok ibu dengan pemeriksaan antenatal $<4$ kali. Sebaliknya persalinan tindakan lebih banyak terjadi pada ibu dengan pemeriksaan antenatal $>4$ kali.

Jenis persalinan yang dilakukan dapat dipengaruhi oleh keinginan ibu. Namun disisi lain, adanya faktor-faktor risiko tertentu juga dapat menentukan dilakukannya persalinan dengan tindakan, seperti usia ibu lebih dari 35 tahun (>35), 
ibu dengan anemia, ibu dengan tekanan darah tinggi, karena kondisi kesehatan umum akan sangat mempengaruhi kondisi kehamilan dan proses persalinan. Adanya keluhan selama kehamilan merupakan faktor risiko terjadi- nya komplikasi persalinan yang akhir-nya terjadi persalinan dengan tindakan.

Penelitian Salusatiaano EMA et al (2012) sebelumnya menunjukkan bahwa kurangnya pemeriksaan antenatal berhubungan dengan skor Apgar yang rendah dengan proses persalinan. Penelitian tersebutsejalan dengan hasilyang didapatkan antara proses persalinan dengan jumlah pemeriksaan kehamilan terhadap hasil skor Apgar. Hasil penelitian menunjukan skor Apgar 0-3 dan 4-6 lebih sering terjadi pada ibu yang melahirkan secara tindakan, sebaliknya nilai skor Apgar 7-10lebih banyak pada ibu yang melahirkan dengan spontan. Hal ini menunjukan bahwa ibu yang memeriksa kehamilan $<4$ kali merupakan salah satu factor resiko terjadinya asfiksia berat pada neonatus dimana $29.9 \%$ ibu akan mengalami proses persalinan tindakan.

Nayeri et al (2012) menyimpulkan bahwa persalinan seksio sesarea darurat, persalinan prematur (<37 minggu), berat badan lahir kurang dari 2500 gram dan anemia neonatal merupakan faktor-faktor yang menyebabkan terjadinya asfiksia. Faktor-faktor tersebut dapat dicegah dengan perawatan persalinan dan pemeriksaan antenatal yang baik.

Penimbangan berat badan pada ibu hamil dilakukan setiap kali kunjungan pemeriksaan kehamilan. Penambahan berat badan yang kurang 9 kilogram selama kehamilan atau kurang dari 1 kilogram setiap bulannya menunjukkan adanya gangguan pertumbuhan janin. Berdasarkan hasil analisis menunjukkan bahwa tidak ada hubungan antara pertambahan berat badan ibu hamil dengan jenis persalinan. Hal ini dimungkinkan pertambahan berat badan yang bertujuan untuk mendeteksi perkembangan janin, yaitu untuk mengetahui apakah janin besar atau pertumbuhan janin kecil dan dimungkinkan bila janin besar bisa terjadi persalinan tidak normal. Namun dalam proses persalinan, janin besar masih bisa melahirkan dengan normal apabila panggul ibu sebagai passageway (jalan lahir) normal, ibu mempunyai power (kekuatan), posisi ibu dalam melahirkan memungkinkan, dan respon psikologis ibu dalam keadaan baik, kemungkinan besar persalinan dapat berlangsung normal (Bobak dkk, 2005). Berdasarkan data juga menunjukkan bahwa pertambahan berat badan yang paling banyak adalah kategori normal $73 \%$ bersalin normal, dan
$18 \%$ bersalin secara normal.

Pada penelitian ini didapatkan proses persalinan berhubungan terhadap berat badan bayi dengan pemeriksaan Kehamilan. Dimana bayi dengan berat badan $<2500$ gram beresiko $13.4 \%$ akan mengalami persalinan dengan tindakan dengan jumlah pemeriksaan antenatal $<4$ kai selama hamil. hal ini sejalan dengan penelitian Deshande, et al. ibu dengan pemeriksaan kehamilan $<4$ kali selama kehamilan memiliki resiko melahirkan bayi dengan berat badan lahir rendah. Demikian juga dalam penelitian Sigh dkk menunjukan bahwa ibu hamil dengan BMl< 20 sangat berpengaruh terhadap persalinan dan Berat Badan lahir Rendah.

Manuaba (2001) menyatakan bahwa usia reproduksi sehat adalah 20 sampai 35 tahun. Pada umur ibu kurang dari 20 tahun dan panggul belum tumbuh mencapai ukuran dewasa. Akibatnya apabila ibu hamil pada umur ini mungkin mengalami persalinan tindakan atau macet, karena ukuran kepala baayi lebih besar sehingga tidakdapat melewati panggul. Sendangkan pada umur ibu yang lebih dari 35 tahun, kesehatan ibu sudah mulai menurun, jalan lahir kaku, sehingga rigiditas tinggi.

Penelitian sebelumnya yang dilakukan oleh Xanda yang menyatakan bahwa ada hubungan antara umur dengan kunjungan Antenatal Care dengan proporsi umur $<20$ atau $>35$ tahun melakukan kunjungan Antenatal lengkap sebesar $36,4 \%$ sedangkan umur 20 - 35 tahun yang melakukan kunjungna lengkap sebesar $66,7 \%$. lbu hamil dengan rentang usia yang produktif yaitu lebih dominan untuk melakukan kunjungan Antenatal Care jika dibandingka dengan rentang usia yang belum produktif ataupun yang sudah tidak produktif.

Pada penelitian ini sejalan dengan penelitian sebelumnya yaitu dimana ibu yang bersalinan dengan spontan pada umur 20-35 tahun dan melakukan pemerisan Anetatal lebih $>4$ kali selama hamil lebih banyak dibandingkan dengan ibu dengan umur rentang $<20$ tahun dan $>35$ tahun. $(p=0,786)$. Berdasarkan hal tersebut adanya keterkaitan antara umur dengan kunjungan antenatal care karena umur 20-35 tahun merupakan umur yang tidak beresiko dalam proses persalinan dan merupakan masa produktif bagi ibu yang secara tidak langsung mampu menumbuhkan keaktifan dalam melakukan kunjungan Antenatal Care secara lengkap selama hamil.

\section{KESIMPULAN}

Adanya hubungaan proses persalinan dengan pemeriksaan Antenatal Care pada hasil 
persalinan dengan kejadian asfiksia berat dan Berat Badan Lahir Rendah. Persalinan dengan komplikasi terjadi pada ibu dengan pemeriksaan Antenatal $<4$ kali.

\section{SARAN}

Bagi petugas pelayanan kesehatan agar lebih meningkatkan deteksi dini faktor risiko pada ibu hamil dengan pemantauan secara aktif pada ibu semasa hamil. Dalam pemeriksaan antenatal dengan kualitas yang baik, termasuk memberikan konseling atau nasehat tentang kehamilan, persalinan, pemberian ASI dan Perawatan bayi, serta anjurkan yang tegas kepada ibu hamil agar bersalin dengan petugas kesehatan.

\section{DAFTAR PUSTAKA}

Abdullah, A., \& Norfai, N. (2018). Analisis Faktor Internal Dan Eksternal Dengan Antenatal Care (ANC) K4 Di Wilayah Kerja Puskesmas Teluk Dalam Kota Banjarmasin Tahun 2017. Jurnal Kesehatan Indonesia, 8(2), 92-99.

Asrinah, P. S. S., Dewi, S., \& Nirmala, S. D. (2010). Asuhan Kebidanan Masa Persalinan. Yogyakarta, Graha IImu.

Bobak, I. M., Lowdermilk, D. L., \& Jensen, M. D. (2005). Keperawatan Maternitas, Edisi 4. Jakarta: EGC.

Dewi, V. N. L., \& Sunarsih, T. (2011). Asuhan Kebidanan untuk Kehamilan.

Kementerian Kesehatan Republik Indonesia. (2017). Profil kesehatan Provinsi Jambi tahun 2016. Jambi: Dinkes ProvinsiJambi

Lihu, F. A. (2015). Analisis Hubungan Antara Faktor Internal dan Faktor Eksternal Ibu Hamil Dalam Melakukan Tindakan Antenatal Care
Di Puskesmas Global Limboto Kabupaten Gorontalo. Jikmu, 5(5).

Manuaba, I. B. G. (2010). IImu kebidanan, penyakit kandungan dan keluarga berencana. Jakarta: EGC, 15, 157.

Nayeri, F., Shariat, M., Dalili, H., Adam, L. B., Mehrjerdi, F. Z., \& Shakeri, A. (2012). Perinatal risk factors for neonatal asphyxia in Vali-e-Asr hospital, Tehran-Iran. Iranian journal of reproductive medicine, 10(2), 137.

Prawirohardjo, S. (2002). Buku Acuan Nasional Pelayanan Kesehatan Maternal dan Neonatal. Jakarta : Bina Pustaka

Rustam, Mochtar.Sinopsis Obstetri Jilid I.Jakarta;EGC.1998

Salustiano, E. M. A., Campos, J. A. D. B., Ibidi, S. M., Ruano, R., \& Zugaib, M. (2012). Low Apgar scores at 5 minutes in a low risk population: maternal and obstetrical factors and postnatal outcome. Revista da Associação Médica Brasileira, 58(5), 587593.

Saufuddin, dkk. (2008). Buku Acuan Nasional Pelayanan Kesehatan Maternal dan Neonatal. Jakarta: Yayasan Bina Pustaka Sarwono Prawirohardjo

Simanjuntak, J., Sondakh, J. M., \& Wagey, F. (2013). Hubungan Jumlah Pemeriksaan Antenatal dengan Hasil Kehamilan dan Persalinan di RSUP Prof. Dr. RD Kandou Manado. eBiomedik, 1(1).

Xanda, A. N. (2015). Faktor-Faktor Yang Berhubungan Dengan Kunjungan Antenatal Care (Di Puskesmas Candipuro Kabupaten Lampung Selatan Tahun 2014). Jurnal Kebidanan Adila Bandar Lampung, 11(2), 28-39. 